\title{
Consumers' Preference and Willingness-To-Pay for Different Varieties of Pepper in Osun State, Nigeria
}

\author{
Olufemi Adedotun Yesufu ${ }^{1, a}$, Ajibola Olajide Ojedokun ${ }^{2, b}$, Mary Adetoun Adegbile ${ }^{1, c, *}$ \\ ${ }^{1}$ Department of Agricultural Economics, Obafemi Awolowo University, Ile-Ife, Osun State, Nigeria \\ ${ }^{2}$ Department of Agriculture, Lagos State University, Epe Campus, Lagos State, Nigeria
}

*Corresponding author

\section{A R T I C L E I F O A B S T R A C T}

Research Article

The study was conducted to assess consumers' preference and willingness to pay for different pepper varieties in Osun State, Nigeria. The study used the major pepper types - Capsicum chinenses (Rodo), C. annum (Tatase), C. frutescens (Sombo) and C. pubescens (Bawa), being sold in the markets in Osun State, Nigeria. A multistage sampling technique was used to collect data from 100 respondents. The primary data collected were analysed using descriptive and inferential statistics. The study showed that consumers mostly preferred and were willing to pay more for $C$. chinenses (Rodo) than any other types of pepper. Household size, primary occupation, total household income, availability and meal-making ability of pepper were the factors that influenced consumers' preference for the different varieties of pepper while the willingness to pay for pepper varieties by consumers was influenced by affordability, availability, taste and thickness. The study

Keywords: recommends that since availability and affordability influenced preference and willingness to pay

Consumers for pepper varieties, policies should be aimed at increasing farmers' production as this will ensure

Pepper that pepper is readily available and affordable for consumers.

Willingness

Multivariate Probit

Hedonic price

olufemi_yesufu@yahoo.com (iD) https://orcid.org/0000-0001-5032-997X

adegbileadetoun@gmail.com

https://orcid.org/0000-0003-4569-4205

ajibola.ojedokun@lasu.edu.ng

iD https://orcid.org/0000-0002-9737-0475

\section{Introduction}

Pepper (Capsicum spp.) is one of the widely used food ingredients and the most widely grown spice crop in the world (Idowu-Agida et al., 2010). It is ranked third among the world's most important vegetable crops, after tomato and onion (Peet, 2006) and considered the first spice to have been used by humans (Hill et al., 2013). It is currently produced in various countries around the world including India, China, Pakistan, Indonesia, Sri Lanka, Thailand, Japan, Ghana, Nigeria, Uganda, and Ethiopia among others (Delelegn, 2011). The Pepper grown worldwide consists of approximately 22 wild species and five domesticated species (C. annum L., C. frutescens L., C. Chinenses., $C$. baccatum L., and $C$. pubescens R.) (Bosland and Votava, 2000). These species can be divided into several groups based on fruit/pod characteristics ranging in pungency, colour, shape, intended use, flavor, and size (Lin et al., 2013).

According to Dipeolu and Akinbode (2007), pepper is a rich source of vitamins such as vitamin $\mathrm{A}, \mathrm{E}$ and $\mathrm{C}$. Pepper contains more vitamin $\mathrm{C}$ than any other vegetable crops. It also acts as a therapeutic agent for cancer and helps in diabetic treatment. Pepper stimulates the flow of saliva, can raise body temperature and may have painrelieving properties (Freudenreich, 2005). Pepper is not only used as a spice in households, but it also provides a variety of needs, such as enhancing the intake of dull diets; storing grains and as mild drugs (Bosland and Votava 2000). It is also used in stew and some local dishes all over the world in varying types and quantities based on different localities and cultures.

Most countries in Africa nurture the culture of spicing up their meals with pepper - making pepper an ingredient of no known close substitute in many African dishes. This has resulted in the mass production of pepper in this part of the world. Pepper production in tropical Africa is estimated at one million tonnes per annum with Nigeria $(715,000 \mathrm{t}$ from 90,000 ha) and Ghana (270,000 t from 75,000 ha) as the largest producers. Nigeria produces $50 \%$ of the total production of different varieties of pepper in Africa (Adesina et al., 2014). The varieties commonly produced in Nigeria include; Bird peppers - Atawere (C.frutescens), Cayenne pepper or red pepper - Sombo (C. frutescens), 
Atarodo or Rodo (C. chinenses), Tatase (C. annum) and Nsukka yellow pepper (Alahira, 2014). These varieties can be used singly or combined together when making sauce or preparing meals. In addition, though, these varieties can be used for the same purposes, consumers' preference for the different varieties have often endeared them towards some particular varieties.

The different varieties of pepper also have different attributes that are peculiar to them and which directly or indirectly stimulate consumers' preferences and willingness to pay. Moreover, the seasonality of pepper causes the price to fluctuate (Dipeolu and Akinbode, 2008) and thus influence consumption patterns, preferences and purchasing behavior. This fluctuation in price has led consumers to move from their preferred type of pepper to other pepper types during periods of scarcity and price increase. Similarly, it is however interesting to note that during periods of scarcity, consumers frequently move from their preferred pepper type to other pepper types and/or reducing the quantity purchased of their preferred pepper type, giving reasons such as high prices, unavailability, low quality among other factors for their behaviour especially during these periods (Adenegan and Adeoye, 2011).

This behavior (of switching to other pepper types) can be influenced by their willingness to pay for their pepper type. Furthermore, previous studies on market research of pepper in Nigeria had been on price analysis of tomato in rural and urban retail markets (Adenegan and Adeoye, 2011), marketing analysis and consumption patterns of tomato (Oladejo and Oladiran, 2014). These studies had not concentrated on consumers' preference and willingness to pay for those pepper types which is necessary for proper production and marketing strategies. There is a thus a need to understand purchasing behavior of consumers for pepper and what factors results in its purchase. Doing this will not only give light to the mostly preferred pepper types but it will also ensure that there is adequate information on the pepper type(s) that consumers are either willing to pay a premium for or discount. Therefore, it is against this background that this study investigated the preference and willingness to pay for pepper varieties and also identified the factors that influenced preference and willingness to pay for different pepper varieties.

\section{Materials and Methods}

The study was carried out in Ife Central Local Government Area (LGA) of Osun State. A multistage sampling procedure was used for the study. The first stage involved a simple random selection of five communities from Ife Central LGA. At the second stage, twenty houses were systematically selected from each community. In the third stage, a consumer was selected from each house through convenience sampling to make a total of one hundred respondents. Primary data were collected with the aid of a well-structured questionnaire. The study used the pepper types that are mostly sold in the market as the required pepper types. They are: Tatase (Capsicum annum), Rodo (Capsicum chinenses), Bawa (Capsicum pubescens), and Sombo (Capsicum frutescens). For uniformity of measurement, the "lambebe" (the smallest container being used to sell pepper in the local market) was converted into kilogramme $(\mathrm{kg})$. The prices and $\mathrm{kg}$ conversion (per lambebe) for each of the pepper type is as follows: Tatase (Capsicum annum): $200 / \mathrm{kg}$, Rodo (Capsicum chinenses): $\$ 170 / \mathrm{kg}$, Bawa (Capsicum pubescens): $210 / \mathrm{kg}$, Sombo (Capsicum frutescens):

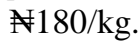

The data collected were analyzed using descriptive statistics, multivariate probit regression model and hedonic-pricing model. Descriptive statistics such as percentages, frequencies and means were employed to describe the socio-economic characteristics of the respondents and to identify consumers' preference for the different pepper types, the multivariate probit regression model was used to identify the factors that influenced the preference for the different pepper types while hedonicpricing model was used to identify the willingness of consumers to pay for the different pepper types.

Factors Influencing Preference for Pepper Varieties: Multivariate Probit Regression Model

In order to determine the factors influencing consumers' preference for different pepper varieties, a multivariate probit regression model was used. This is because of the assumption that preference decisions among the different pepper types are not mutually exclusive as consumers can prefer and use more than one pepper type at a time for cooking and therefore, the random error components of the pepper types may be correlated. Thus for the purpose of this study, the estimation began with a probit model. The probit model was used because its likelihood function is well-behaved as it gives consistent Maximum Likelihood Estimate (MLE) coefficients $(\beta)$ and standard error of the estimate(s) (Maddala, 1992). The probit model estimates the probability of preferring pepper types for a consuming household level data and measures this likelihood after controlling the relevant variables used in the model. The dependent variable in the first step was defined as a dichotomous variable with the values 1 for those who prefer and 0 for those who do not prefer.

To estimate the preference equations for all the pepper types, the simplest and most straight forward estimation procedure would be to estimate each probit equation separately. However, it is important to note that the data for the different pepper types were collected from one individual consumer at a given point in time. This may bring endogeneity within the data set that is, the error terms between the equations of different peppers might be correlated since data is being collected from the same individual whose decision on a particular pepper may affect the probability of selecting another pepper. As such, multivariate probit model was used to address this problem. Following Cappellari and Jenkins (2003), the multivariate probit model was structured as follows. Consider the M-equation multivariate probit model:

$$
\begin{aligned}
& \mathrm{y}_{\mathrm{im}}^{*}=\beta_{\mathrm{m}}{ }^{\prime} \mathrm{X}_{\mathrm{im}}+\epsilon_{\mathrm{im}}, \mathrm{m}=1, \ldots, \mathrm{M} \\
& \mathrm{y}_{\mathrm{im}}^{*}=1 \text { if } \mathrm{y}_{\mathrm{im}}^{*}>0 \text { and } 0 \text { otherwise }
\end{aligned}
$$

$\epsilon_{i m}, m=1, \ldots, M$ are error terms distributed as multivariate normal, each with a mean of zero, and variance-covariance matrix $\mathrm{V}$, where $\mathrm{V}$ has value of 1 on the leading diagonal and correlations $\rho_{j k}=\rho_{k j}$ as off 
diagonal elements. The multivariate probit model has a structure like the Seemingly Unrelated Regression (SUR), except that the dependent variables are binary indicators. The $y_{i m}$ might represent outcomes for $M$ different preferences at the same point in time, for example, whether a consumer chooses $M$ type of peppers. The $X_{i m}$ is a vector of explanatory variables and $\beta_{m}$ are unknown parameters to be estimated. The probability function of the probit model is usually the standard normal density which provides predicted values within the range $(0,1)$. Therefore, a multivariate model allowing for the possible contemporaneous correlation in the decisions to choose the different peppers can be specified as follows:

$$
y_{i j}=x_{i j}^{I} \beta_{j}+\varepsilon_{i j}
$$

$$
\begin{aligned}
& \text { Where } \\
& \begin{array}{ll}
\mathrm{i} \quad=\text { observation of consuming household; } \\
\mathrm{j} \quad=\text { the number of peppers }(\mathrm{j}=1, \ldots, 4) ; \\
\varepsilon_{i j} \quad=\text { unobserved error term; } \\
\mathrm{y}_{\mathrm{i}} \quad=\text { pepper preferred by consumer; }
\end{array}
\end{aligned}
$$

Prob $\left(y_{i}=j\right)=$ probability of preferring any of the selected peppers;

$$
\begin{aligned}
& y_{1}^{*}=\alpha_{1}+X \beta_{1}+\varepsilon_{1} \\
& y_{2}^{*}=\alpha_{2}+X \beta_{2}+\varepsilon_{2} \\
& y_{3}^{*}=\alpha_{3}+X \beta_{3}+\varepsilon_{3} \\
& y_{4}^{*}=\alpha_{4}+X \beta_{4}+\varepsilon_{4}
\end{aligned}
$$

With $y_{1}^{*}, y_{2}^{*}, y_{3}^{*}$, and $y_{4}^{*}$ a set of n-latent variables underlying each of the pepper preference such that $y_{j}=1$ if $y_{j}^{*}>0 ; 0$ otherwise.

$\beta=$ the coefficients' vector;

$\mathrm{X}_{\mathrm{i}}=$ vector of consumer characteristics,

where:

$\mathrm{X}_{1} \quad$ age of consumer (years);

$\mathrm{X}_{2}=$ household size (number);

$\mathrm{X}_{3}=$ sex of consumer (dummy $1=$ male and $0=$ female);

$\mathrm{X}_{4}=$ number of years spent in education (Years);

$\mathrm{X}_{5}=$ Primary occupation (dummy 1 = civil servant and $0=$ others);

$\mathrm{X}_{6} \quad=$ Income (natural logarithm);

$\mathrm{X}_{7}=$ Affordability (dummy $1=$ yes and $0=$ no);

$\mathrm{X}_{8}=$ Availability (dummy $1=$ yes and $0=$ no);

$\mathrm{X}_{9} \quad=$ Taste $($ dummy $1=$ yes and $0=$ no);

$\mathrm{X}_{10}=$ Health related (dummy $1=$ yes and $0=$ no);

$\varepsilon_{i} \quad=$ Error term

\section{Willingness-To-Pay for Pepper Varieties: Hedonic Pricing Model}

This is based on Lancaster's (1996) model of consumption theory. He regards the characteristics of the good and not the good itself as the direct object of utility. This concept has widely been used to estimate willingness to pay for quality of goods. Thus, price differences across different units of transactions are due mainly to quality differences that can be measured in terms of the characteristics. Ladd and Suvannunt (1976) used this concept to develop the consumer goods characteristics model which describes the price of a good as a linear summation of the implicit values of its attributes. For this study, revealed preferences as a measure of willingness to pay for pepper was used as the dependent variable in the hedonic model.

Different researchers (Lowenberg-DeBoer, 2001; Mundua, 2011; Ibrahim et al., 2013; Kalu and Ajetunmobi, 2013) have estimated the hedonic function using a regression technique. The consumer's commodity prices are regressed against the commodity characteristics to derive a coefficient representing the implicit price of the characteristics. The hedonic price function following Faye et al.(2002) is specified below:

$$
\mathrm{P}_{\mathrm{i}}=\alpha_{0}+\beta_{\mathrm{ik}} \sum_{\mathrm{i}=1}^{\mathrm{j}=1} \mathrm{Z}_{\mathrm{ik}}+\mu
$$

Where $P_{i}$ is the price per unit of each pepper type, $\alpha_{0}$ is the constant or intercept, $\beta_{\mathrm{ik}}$ is the marginal value of characteristics $\mathrm{k}$ in good $\mathrm{i}, \mathrm{Z}_{\mathrm{ik}}$ is the amount of characteristics $\mathrm{k}$ in good $\mathrm{i}, \mu$ is the error term.

For this study, the Hedonic price function in equation (4) was expressed in the following form:

$\mathrm{P}_{\mathrm{i}}=\alpha_{0}+\alpha_{1} \mathrm{Z}_{\mathrm{i} 1}+\alpha_{2} \mathrm{Z}_{\mathrm{i} 2}+\alpha_{3} \mathrm{Z}_{\mathrm{i} 3}+\alpha_{4} \mathrm{Z}_{\mathrm{i} 4}+\alpha_{5} \mathrm{Z}_{\mathrm{i} 5}+\ldots+\alpha_{\mathrm{n}} \mathrm{Z}_{\mathrm{in}}+\mu(5)$

Where $P_{i}$ is the willingness to pay for a type of pepper in $\mathrm{N} / \mathrm{kg}, \mathrm{Z}_{1}$ is the consumption attribute, $\mu$ is the error term. The different attributes for pepper were entered as dummy variables. The approach used to create dummies for taste was to assign a value of one for sweet taste and zero otherwise. A value of one was assigned to affordability and zero otherwise. A value of one was assigned to availability and zero otherwise. Also, a value of one was assigned to if it is related to health issues and zero otherwise. The choice of these classes of dummy variables as base variables was important because it allowed for positive values of the regression coefficients for ease of interpretation of the results. For the expected signs for estimated parameters, the different attributes examined are expected to have positive signs.

\section{Results and Discussion}

\section{Description of Respondents by Their Socio-Economic Characteristics}

The descriptive statistics of the respondents were presented in Table 1. The result showed that the mean age of respondents was approximately 36 years. This finding indicates that respondents were mostly middle-aged, active and agile. This result conforms to the findings of Yeh and Hartmann (2016), who reported similar findings in their study on sweet pepper. The sex distribution of the respondents showed that majority $(65.0 \%)$ of the respondents considered were female. The results obtained also indicate that the majority $(67.0 \%)$ of the respondents were married. This implication of this is that those who are married would have more household size which will cause them to increase the quantity of pepper that is purchased and consumed compared to those who are not married. This result conforms to the findings of Khaliukova (2013), who in her study on pepper also reported more married pepper consumers. 
Table 1. Socio-economic characteristics of pepper consumers

\begin{tabular}{|c|c|c|c|}
\hline & Socio-economic characteristics & Frequency & Percentage \\
\hline \multirow{7}{*}{ Age (years) } & $21-30$ & 29 & 29.0 \\
\hline & $31-40$ & 47 & 47.0 \\
\hline & $41-50$ & 14 & 14.0 \\
\hline & $51-60$ & 8 & 8.0 \\
\hline & $61-70$ & 2 & 2.0 \\
\hline & Mean (Standard deviation) & \multicolumn{2}{|c|}{$35.93(9.95)$} \\
\hline & Male & 35 & 35.0 \\
\hline & Female & 65 & 65.0 \\
\hline \multirow[t]{3}{*}{ Sex } & Marital status & & \\
\hline & Married & 67 & 67.0 \\
\hline & Single & 33 & 33.0 \\
\hline \multirow[t]{4}{*}{ Number of years of education attained } & 0 & 6 & 6.0 \\
\hline & $1-10$ & 30 & 30.0 \\
\hline & $11-20$ & 64 & 64.0 \\
\hline & Mean (Standard deviation) & \multicolumn{2}{|c|}{$12.38(4.71)$} \\
\hline \multirow[t]{8}{*}{ Primary occupation } & Civil servant & 31 & 31.0 \\
\hline & Artisan & 26 & 26.0 \\
\hline & Private salary earner & 15 & 15.0 \\
\hline & Trader & 28 & 28.0 \\
\hline & Household size & & \\
\hline & $1-4$ & 72 & 72.0 \\
\hline & $5-8$ & 28 & 28.0 \\
\hline & Mean (Standard deviation) & \multicolumn{2}{|c|}{$3.30(1.73)$} \\
\hline \multirow[t]{6}{*}{ Total household income ( } & $>51,000$ & 37 & 37.0 \\
\hline & $51,000-100,000$ & 41 & 41.0 \\
\hline & $100,001-150,000$ & 8 & 8.0 \\
\hline & $150,001-200,000$ & 7 & 7.0 \\
\hline & $<200,000$ & 7 & 7.0 \\
\hline & Mean (Standard deviation) & \multicolumn{2}{|c|}{$82115.00(54473.41)$} \\
\hline
\end{tabular}

Source: Data Analysis, 2020

The result showed that the mean number of years spent in attaining formal education was approximately 12 years, hence, respondents can read and write. This is also expected to have an impact on their choice of pepper (Asano and Fiuza, 2003).

The result in Table 1 also revealed that majority $(85.0 \%)$ of the respondents are either civil servants, artisans or traders. The primary occupation of consumers according to Obayelu et al.(2009) have been observed to have an effect on their consumption of pepper. The mean household size of the respondents was approximately 3 members. The implication of this is that households with more members are expected to purchase and consume more pepper than households with fewer members. The mean total household monthly income of consuming households was $\$ 82,115.00$. This shows that consuming households will have more disposable income which could be used to purchase pepper.

\section{Identification of Consumers' Preference for Pepper}

The result in Table 2 showed that $75.0 \%$ of the consumers preferred Tatase (Capsicum annum), 91.0\% preferred Rodo (Capsicum chinenses), $73.0 \%$ preferred Bawa (Capsicum pubescens) while 56.0\% preferred Sombo (Capsicum frutescens). The results further showed that the consumers preferred Tatase (Capsicum annum), because of its availability $(73.0 \%)$ and price $(68.0 \%)$. Also, the consumers preferred Rodo (Capsicum chinenses) because of its availability $(88.0 \%)$ and affordability $(86.0 \%)$. In addition, the consumers preferred Bawa (Capsicum pubescens) because of its availability (71.0\%) and affordability $(70.0 \%)$. Finally, those who preferred Sombo (Capsicum frutescens) did because of its availability (54.0\%) and affordability (52.0\%).

Overall, the result showed that majority $(66.0 \%)$ of the consumers preferred Rodo (Capsicum chinenses) over other types of pepper. This is followed by Tatase (Capsicum annum) (16.0\%), Bawa (Capsicum pubescens) $(12.0 \%)$ while Sombo (Capsicum frutescens) $(6.0 \%)$ is the least preferred type of pepper. The fact that consumers mostly preferred Rodo (Capsicum chinenses) over other types of pepper is because even during scarcity of pepper when other pepper types are expensive, Rodo (Capsicum chinenses) was always available and the quantity sold per unit was more than other types of pepper. Also, Rodo (Capsicum chinenses) when prepared alone has a good taste unlike other pepper type which when prepared individually is bland and tasteless. The implication of this result is that consumers will buy more of Rodo (Capsicum chinenses) than any other type of pepper.

\section{Factors Influencing Consumers' Preference for} Pepper

The result of the multivariate probit model as presented in Table 3 revealed that the log-likelihood function was 179.549, the Wald chi $^{2}$ was 60.42 and that the Prob>chi ${ }^{2}$ was 0.0017 indicating that the entire model was significant at the $1 \%$ level of significance. These diagnostic variables and the significance level reveal the fitness of the entire model. 
Table 2. Preference of consumers for pepper

\begin{tabular}{|c|c|c|c|c|}
\hline Pepper & Preference & Mostly preferred & Attributes & Frequency $(\%)$ \\
\hline \multirow{4}{*}{ Tatase (Capsicum annum) } & \multirow{4}{*}{$75(75.0)$} & \multirow{4}{*}{$16(16.0)$} & Price & $68(68.0)$ \\
\hline & & & Affordability & $65(65.0)$ \\
\hline & & & Availability & $73(73.0)$ \\
\hline & & & Health-related & $40(40.0)$ \\
\hline \multirow{4}{*}{ Rodo (Capsicum chinenses) } & \multirow{5}{*}{$91(91.0)$} & \multirow{5}{*}{$66(66.0)$} & Price & $78(78.0)$ \\
\hline & & & Affordability & $86(86.0)$ \\
\hline & & & Availability & $88(88.0)$ \\
\hline & & & Health-related & $45(45.0)$ \\
\hline \multirow{4}{*}{ Bawa (Capsicum pubescens) } & & & Price & $69(69.0)$ \\
\hline & \multirow{3}{*}{$73(73.0)$} & \multirow{3}{*}{$12(12.0)$} & Affordability & $70(70.0)$ \\
\hline & & & Availability & $71(71.0)$ \\
\hline & & & Health-related & $41(41.0)$ \\
\hline \multirow{4}{*}{ Sombo (Capsicum frutescens) } & \multirow{4}{*}{$56(56.0)$} & \multirow{4}{*}{$6(6.0)$} & Price & $46(46.0)$ \\
\hline & & & Affordability & $52(52.0)$ \\
\hline & & & Availability & $54(54.0)$ \\
\hline & & & Health-related & $48(48.0)$ \\
\hline
\end{tabular}

Table 3. Factors influencing the preference for pepper

\begin{tabular}{l|cccc}
\hline Variable & Tatase & Rodo & Bawa & Sombo \\
\hline Age & $-0.85(-1.25)$ & $-1.447(-1.31)$ & $0.566(0.77)$ & $-0.068(-0.12)$ \\
Household size & $-0.135(-0.68)$ & $0.570^{*}(1.67)$ & $0.209(0.94)$ & $-0.284(-1.53)$ \\
Income & $0.378^{*}(1.66)$ & $-0.144(-0.36)$ & $-0.533 * *(-2.05)$ & $-0.072(-0.38)$ \\
Primary occupation & $0.622^{*}(1.73)$ & $-0.353(-0.76)$ & $0.776^{* *}(2.08)$ & $0.184(0.64)$ \\
Affordable & $-1.151(-1.10)$ & $-4.075(-0.04)$ & $-0.552(-0.74)$ & $0.990(1.24)$ \\
Available & $0.807(1.44)$ & $0.969(1.19)$ & $1.000^{*}(1.91)$ & $0.473(0.92)$ \\
Meal-making ability & $-0.176(-0.41)$ & $-2.517(-0.13)$ & $0.759 * *(2.05)$ & $-0.062(-0.18)$ \\
Health related & $-0.080(-0.27)$ & $-0.767(-1.59)$ & $0.396(1.27)$ & $0.200(0.73)$ \\
Constant & $-2.922(-1.02)$ & $13.843(0.12)$ & $2.975(1.08)$ & $-1.776(-0.70)$ \\
Rho21 & $0.408^{*}(1.67)$ & & & \\
Rho31 & $0.227(1.09)$ & & & \\
Rho41 & $0.503 * *(3.29)$ & & & \\
Rho32 & $-0.527(-1.41)$ & & & \\
Rho42 & $0.553 * *(2.60)$ & & & \\
Rho43 & $0.071(0.38)$ & & & \\
Log likelihood & -179.549 & & & \\
Wald chi & 60.42 & & & \\
Prob>chi & 0.0017 & & & \\
\hline
\end{tabular}

Likelihood ratio test of the correlation coefficients of the pepper types rho $21=\operatorname{rho} 31=\operatorname{rho} 41=\operatorname{rho}_{2}=\operatorname{rho}_{2}=\mathrm{rho}_{3}=0: \mathrm{chi}^{2}(6)=17.3731 ; \mathrm{Prob}>$ $\mathrm{chi}^{2}=0.0080$. The figures in parenthesis represents the t-value while the $* * *$ and $* * *$ represents $10 \%, 5 \%$ and $1 \%$ level of significance respectively.

The result revealed that the coefficient of household size was positive and statistically significant for Rodo (Capsicum chinenses) at $10 \%$ level of significance. This implies that as the members within a consuming household increases, the likelihood of that household preferring and using Rodo (Capsicum chinenses) would also increase. This is not farfetched because on one hand, Rodo (Capsicum chinenses) when prepared alone has a good taste and on the other hand, it is always available and the quantity sold per unit is more than other types of pepper even during the scarcity of pepper when other pepper types are expensive. The result also showed that the coefficient of total household income was significant for Tatase (Capsicum annum) and Bawa (Capsicum pubescens) at $10 \%$ and $5 \%$ respectively. The result showed that whilst the coefficient of total household income was positively significant for Tatase (Capsicum annum), it was negatively significant for Bawa (Capsicum pubescens). This indicates that whilst an increase in the total income of a consuming household will increase the likelihood of that household preferring and using Capsicum annum, an increase in total household income will reduce the likelihood of consuming households preferring and using Capsicum pubescens. The positive significance of total household income with Capsicum annum is because Capsicum annum makes sauce very thick and rich when compared with Capsicum pubescens and as such consuming households with increased total income would be endeared towards it.

The result also revealed that the coefficient of primary occupation was positive and statistically significant for Tatase (Capsicum annum) and Bawa (Capsicum pubescens) at 10\% and $5 \%$ respectively. The positive sign indicates that consumers who are civil servants will more likely prefer and use these two pepper types. Furthermore, the coefficient of availability was positive and statistically significant for Bawa (Capsicum pubescens) at $10 \%$. This implies that consuming households will more likely prefer Capsicum pubescens because it is available. Finally, the coefficient of meal-making ability was positively significant for Bawa (Capsicum pubescens) at 5\% which indicates that consuming households will more likely prefer and use Capsicum pubescens for their cooking. This is true as Capsicum pubescens adds colour to 
sauce and other meals. It is known for its peculiar "reddish colour", thus making it suitable for different meals.

The expected multivariate interdependence of preference and use of the different pepper types were accounted for employing the multivariate probit simulation of the four pepper types. The null hypothesis that the correlations are jointly zero and the four decisions to prefer and use are independent was rejected at the $1 \%$ significance level. The results revealed that Rodo (Capsicum chinenses) enhanced the preference and use of Tatase (Capsicum annum). This is because the combination of these two pepper types always enhances the taste, thickness and richness of sauce or meals prepared (rho21). Also, the result showed positive interdependence of Sombo (Capsicum frutescens) and Tatase (Capsicum annum) (rho41). The positive interdependence is because Capsicum frutescens has the same characteristics as Capsicum chinenses, though it is bigger and longer than Capsicum chinenses. Hence, it can be combined with Capsicum annum just like Capsicum chinenses could be combined with Capsicum annum. The result also showed positive interdependence of Sombo (Capsicum frutescens) and Rodo (Capsicum chinenses). As stated earlier, these two pepper types have the same characteristics save for the difference in the size of the two. The positive interdependence indicates that the use of one pepper type gives the consumer the avenue to use another pepper type. Therefore, the positive interdependence showed that consumers' decision to prefer and use a pepper type does not affect or alter the decision to prefer and use another pepper type. Furthermore, the positive interaction showed that the activities done to promote one pepper type would also promote another pepper type.

\section{Consumers' Willingness to Pay for The Preferred}

\section{Pepper Type}

The market price for each of the pepper types in $N / \mathrm{kg}$ was given in the materials and method section. Hence, the result in Table 4 revealed that consumers were willing to pay a premium of $109.33 / \mathrm{kg}$ for Tatase (Capsicum annum), $152.02 / \mathrm{kg}$ for Rodo (Capsicum chinenses), $\$ 92.03 / \mathrm{kg}$ for Bawa (Capsicum pubescens) and $\$ 84.56 / \mathrm{kg}$ for Sombo (Capsicum frutescens). The study further revealed that pepper consumers were more willing to pay for Rodo (Capsicum chinenses) than any other pepper type. This is because Rodo (Capsicum chinenses) is the best pepper type when used and prepared as sauce alone compared to others. The willingness to pay of consumers for Capsicum chinenses is also because it is readily available and affordable.

Factors Influencing the Willingness to Pay for Pepper

The result in Table 5 showed that all the estimations are significant at $1 \%$ alpha level and that the coefficient of determination $\left(\mathrm{R}^{2}\right)$ for each of the pepper types are 0.7400 , $0.8334,0.7240$ and 0.6248 respectively. This implies that the independent variables were able to explain about $74.0 \%, 83.3 \%, 72.4 \%$ and $62.5 \%$ of the total variations in the willingness to pay of pepper consumers for the different types of pepper respectively.

The result further showed that the coefficient of affordability for Tatase (Capsicum annum), Rodo (Capsicum chinenses), Bawa (Capsicum pubescens) and Sombo (Capsicum frutescens) was positive and statistically significant at $5 \%$ and $1 \%$ respectively. This result shows that due to the affordability of these different types of pepper, consumers would be willing to pay a premium of ¥2.60, 2.66 , 3.87 , 33.67 for Tatase (Capsicum annum), Rodo (Capsicum chinenses), Bawa (Capsicum pubescens) and Sombo (Capsicum frutescens) respectively. The result also revealed that the coefficient of availability was positive and statistically significant for Capsicum annum at $10 \%$. This indicates that consumers would be willing to pay a premium of $\$ 2.06$ for Capsicum annum because it is available.

Table 4. Distribution of consumers by willingness to pay for the preferred pepper type

\begin{tabular}{l|cc}
\hline \multicolumn{1}{c|}{ Pepper type } & Average Willingness to Pay (AWP) $\mathrm{N} / \mathrm{kg}$ & Standard Deviation \\
\hline Tatase & 309.33 & 136.73 \\
Rodo & 322.02 & 115.89 \\
Bawa & 302.03 & 143.11 \\
Sombo & 264.53 & 127.32 \\
\hline
\end{tabular}

Source: Field Survey, 2020

Table 5. Factors influencing the willingness to pay for pepper

\begin{tabular}{l|cccc}
\hline Variable/Pepper & Tatase & Rodo & Bawa & Sombo \\
\hline Price & $-1.491(-1.20)$ & $-0.137(-0.14)$ & $0.899(0.74)$ & $-0.200(-0.15)$ \\
Affordability & $2.604 * *(2.32)$ & $2.661 * * *(2.89)$ & $3.867 * * *(3.50)$ & $3.365 * * *(2.86)$ \\
Availability & $2.058^{*}(1.69)$ & $1.443(1.45)$ & $0.442(0.37)$ & $1.658(1.30)$ \\
Taste & $0.287(0.26)$ & $0.186(0.20)$ & $-2.592 * *(-2.30)$ & $-2.322 *(-1.93)$ \\
Meal-making ability & $0.534(0.73)$ & $0.884(1.47)$ & $-0.042(-0.06)$ & $-0.1689-0.22)$ \\
Health-related & $0.052(0.09)$ & $-0.375(-0.83)$ & $-0.676(-1.24)$ & $-0.015(-0.03)$ \\
Thickness & $0.802(1.38)$ & $0.130(0.27)$ & $1.617 * * *(2.82)$ & $0.315(0.52)$ \\
Constant & $6.256(4.27)$ & $4.366(3.55)$ & $3.806(2.50)$ & $4.047(2.49)$ \\
R-squared & 0.7400 & 0.8334 & 0.7240 & 0.6248 \\
Adjusted R-squared & 0.7205 & 0.8209 & 0.7033 & 0.5965 \\
F & $37.82 * * *$ & $66.48 * * *$ & $34.85 * * *$ & $22.12 * * *$ \\
\hline
\end{tabular}


The result further showed that the coefficient of taste concerning Bawa (Capsicum pubescens) and Sombo (Capsicum frutescens) were negative and statistically significant at $5 \%$ and $10 \%$ respectively. This result indicates that due to the taste of these two types of pepper, consumers would discount a price of $\$ 2.59$ and $\$ 2.32$ Bawa (Capsicum pubescens) and Sombo (Capsicum frutescens) respectively. Finally, the result showed that the coefficient of thickness was positive and statistically significant for Bawa (Capsicum pubescens) at $1 \%$, which implies that consumers would be willing to pay a premium of 1.62 for Capsicum pubescens because of its thickness

\section{Conclusion and Recommendations}

The study was conducted to assess consumers' preference and willingness to pay for different pepper varieties in Osun State, Nigeria. The study used the major pepper types being sold in the markets in Osun State, Nigeria. The study therefore concluded that consumers mostly preferred and were willing to pay more for Rodo than any other types of pepper. Household size, primary occupation, total household income, availability and mealmaking ability of pepper were the factors that influenced consumers' preference for the different pepper varieties while the factors which influenced willingness to pay for pepper varieties are affordability, availability, taste and thickness. The study therefore recommended that since availability and affordability influenced preference and willingness to pay for different pepper varieties, policies should be aimed at increasing farmers' production, doing this will ensure that pepper is readily available and consequently, affordable for consumers. Finally, the result showed that household income significantly influenced preference for pepper varieties, hence, policies should be made at ensuring that the income of consumers are not adversely affected.

\section{References}

Adenegan KO, Adeoye IB. 2011. Price analysis of tomato in rural and urban retail markets of Oyo State. International Journal of Agricultural Economics and Rural Development, 4(2): 90 -96. DOI: 10.2298/JAS1303195O.

Adesina JM, Sanni KO, Afolabi LA, Eleduma AF. 2014. Effect of variable rate of poultry manure on the growth and yield of pepper (Capsicum annum) in South Western Nigeria. Academic Arena, 6(1): 9-13. Available from: http://sciencepub.net/academia/aa0601/002_22555aa0601_9 13.pdf [Accessed on: 12.01.2021].

Alahira J. 2014. Practical information about pepper production. Available from: https://www.agriculturenigeria.com/manuals/ production/crop-production/horticulture/pepper-production/. [Accessed on 12/01/2021]

Asano S, Fiuza EP. 2003. Estimation of the Brazilian consumer demand system. Brazilian Review of Econometrics, 23(2):255294. Available from: http://repositorio.ipea.gov.br/ bitstream/11058/2355/1/TD_793.pdf [Accessed on: 12.01.2021].

Bosland PW, Votava EJ. 2000. Peppers: vegetable and spice capsicums. Crop Production Science in Horticulture 12. CAB International Publishing, Wallingford, England, UK. 204 pp. DOI: 10.1080/01140671.2012.745161.

Cappellari L, Jenkins S. 2003. Multivariate probit regression using simulated maximum likelihood. The Stata Journal, 3(3): 278 - 294. DOI: $10.1177 / 1536867$ X0300300305.
Delelegn S. 2011. Evaluation of Elite hot pepper varieties (Capsicum species) for growth, dry pod yield and quality under Jimma condition, South West Ethiopia. An unpublished MSc thesis in Horticulture (Vegetable Science), Jimma University, Jimma, Ethiopia. Available from: https://cgspace.cgiar.org/handle/10568/3613. [Accessed on: 13.02.2021].

Dipeolu AO, Akinbode SO, Okuneye AP. 2007. Income generating potentials of street food vending businesses in Ogun State, Nigeria. Asset, Series C, 2(1): 180 - 189. DOI: 10.1080/10496505.2011.563226

Dipeolu AO, Akinbode SO. 2008. Technical, economic and allocative efficiencies of pepper production in South-West Nigeria: a stochastic frontier approach. Journal of Economics and Rural Development 17(1): 24-33. DOI: 10.22004/ag.econ.147641

Faye MD, Ndiaye M, Lowenberg-Deboer J. 2002. Identifying Cowpea Characteristics which command Price Premiums in Senegalese Markets - An Overview. Proceedings of the Third World Cowpea Conference, Ibadan, Nigeria, September 2002: 424 - 433. Available from: https://www.tandfonline.com/doi/abs/10.1080/ 03031853.2004.9523658. [Accessed on: 13.02.2021].

Freudenreich O. 2005. Drug induced sialorrhea. Drugs of Today (Barc), 41: 411 - 418. DOI: 10.1358/dot.2005.41.6.893628

Hill TA, Ashrafi H, Reyes-Chin-Wo S, Yao J, Stoffel K, Truco MA, Kozik A, Michelmore RW, Deynze AV. 2013. Characterization of Capsicum annuum genetic diversity and population structure based on parallel polymorphism discovery with a $30 \mathrm{~K}$ Unigene Pepper GeneChip. Plos One, 8(2): 1 - 16. DOI: 10.1371/journal.pone.0056200

Ibrahim FD, Nmadu JN, Baba KM, Gana AS, Danbaba N, Ibrahim PA. 2013. Demand analysis for consumer preference of cowpea attributes in Niger State: A Hedonic Approach. IOSR Journal of Agriculture and Veterinary Science, 5(5): 67 - 72. Available from: http://www.iosrjournals.org/ccount/ click.php?id=8110. [Accessed on: 13.02.2021].

Idowu-Agida OO, Nwaguma EI, Adeoye IB. 2010. Cost implication of wet and dry season pepper production in Ibadan, South Western Nigeria. Agricultural and Biological Journal of North American, 1(4): 495 - 500. Available from: https://scihub.org/ABJNA/PDF/2010/4/1-4-495-500.pdf. [Accessed on: 13.02.2021].

Kalu UI, Ajetunmobi JO. 2013. Consumers' preference for cowpea in Nigeria. International Journal of Agricultural Management and Development: $19-26$. Available from: http://ijamad.iaurasht.ac.ir/article_513875.html. [Accessed on: 13.02.2021].

Khaliukova O. 2013. Demand analysis for tomato, onion, peppers, and fresh okra in Nigeria. Master's Thesis, University of Tennessee. Available from: https://trace.tennessee.edu/utk_gradthes/2616/. [Accessed on: 13.02.2021].

Ladd GW, Suvannunt V. 1976. A model of consumer goods characteristics. American Journal of Agricultural Economics. 58(3): 504 - 510. Available from: https://econpapers.repec.org/ scripts/redir.pf?u=http\%3A\%2F\%2Fhdl.handle.net $\% 2 \mathrm{~F} 10.2$ 307\%2F1239267;h=repec:oup:ajagec:v:58:y:1976:i:3:p:504510. [Accessed on: 13.02.2021].

Lancaster KJ. 1966. A new approach to consumer theory. Journal of Political Economy, 74(2): 132 - 157. Available from: https://www.jstor.org/stable/1828835?seq=1. [Accessed on: 13.02.2021].

Lin S, Chou Y, Shieh H, Ebert AW, Kumar S, Mavlyanov R, Tenkouano A, Afari-Sefa V, Gniffke PA. 2014. Pepper (Capsicum spp.) germplasm dissemination by AVRDC - the world vegetable center: an overview and introspection. Chronica Horticulturae, 53(3): $20-27$. Available from: https://www.researchgate.net/publication/257363507. [Accessed on: 13.02.2021]. 
Lowenberg-DeBoer J. 2001. Trip report - bean/cowpea collaborative research support progam, Purdue University. Available from: https://www.entm.purdue.edu/NGICA/ reports/Malawi.pdf. [Accessed on: 13.02.2021].

Maddala GS. 1992. Introduction to econometrics. Second edition. New York: Macmillan Publishing Company. Available from: https://jigjids.files.wordpress.com/2011/05/introduction-toeconometric-2nd.pdf. [Accessed on: 13.02.2021].

Mundua J. 2011. Estimation of consumer preferences for cowpea varieties in Kumi and Soroti Districts. Unpublished M.Sc. Thesis. Makarere University Uganda. Available from: http://hdl.handle.net/10570/2900. [Accessed on: 13.02.2021]

Obayelu AE, Okoruwa VO, Ajani OIY. 2009. Cross-sectional analysis of food demand in the North Central, Nigeria: The quadratic almost ideal demand system (QUAIDS) approach. China Agricultural Economic Review, 1: 173-193. Available from: https://econpapers.repec.org/scripts/redir.pf?u=http\%3A $\% 2 \mathrm{~F} \% 2 \mathrm{Fwww} . e m e r a l d i n s i g h t . c o m \% 2 \mathrm{~F} 10.1108 \% 2 \mathrm{~F} 175613$ 70910927426\%3Futm_campaign\%3DRePEc\%26WT.mc_id \%3DRePEc;h=repec:eme:caerpp:v:1:y:2009:i:2:p:173-193. [Accessed on: 13.02.2021]
Oladejo JA, Oladiran JO. 2014. Marketing analysis and consumption pattern of tomato in Oyo State, Nigeria. International Journal of Agriculture Innovations and Research, 2(5): $811-817$. Available from: https://www.researchgate.net/profile/Joana_Oladejo/publicat ion/262359521_Marketing_Analysis_and_Consumption_Pat tern_of_Tomato_in_Oyo_State_Nigeria/links/0deec538a50f a398f2000000.pdf. [Accessed on: 13.02.2021]

Peet M. 2006. Sustainable practices for vegetable production in South Carolina Crop new profile pepper. NCSU, USA. Available from: https://scialert.net/fulltext/?doi=ja.2011.62.67 \&org=11. [Accessed on: 13.02.2021]

Yeh C, Hartmann M. 2016. Consumers' preference for sweet peppers with different process attributes: A discreet choice experiment in Taiwan. International Journal on Food System Dynamics: 268 - 287. DOI: 10.22004/ag.econ.244551 